\title{
Molecular Identification of Lactic Acid Bacteria Isolated from the Traditional Fermented Yak Yogurt in Western Sichuan Region
}

\author{
Lu Ren ${ }^{1,2}$ Huayi SUO 1,2,* \\ ${ }^{1}$ College of Food Science, Southwest University, Chongqing 400715, China \\ ${ }^{2}$ Chongqing Engineering Research Center of Regional Food, Chongqing 400715, China
}

Keywords: Yak yogurt; Lactic acid bacteria; 16S rDNA; Molecular identification

\begin{abstract}
He 32 strains genetically stable and vigorous lactic acid bacteria isolated from fermented yak milk made by tibetans in Sichuan that were performered microscopic examination ,including 10 strains of Lactobacillus and 22 strains of Lactococcus after cultured, followed DNA extraction, PCR amplification. The sequencing results were submitted to NCBI database for sequence alignment (identities $>97.5 \%$ ). Showed there are 5 main spcies in the traditional fermented yak yogurt: Lactobacillus 5 strains (15.6\%), Lactococcus 3 strains (9.4\%), Leuconostoc 3 strains (9.4\%), Bacillus 3 strains (9.4\%), Enterococcus 16 strains (50.0\%), with two strain identified unsuccessfully (No. 31 and 32, the preliminary result is Lactobacillus, identities is 95.0\%). Then established the phylogenetic tree based on 16S rDNA sequence with MEGA5.05 software to analyze and provide theory reference for lactic acid bacteria genetic diversity in yak milk from the western Sichuan basin.

Yak is a rare species mainly distributed in Tibet, Sichuan, Qinghai, Gansu and other regions. With the merits of withstanding cold weather and low temperature as well as tolerance to hypoxia, yak is praised as the "boat on the plateau" [1-3]. It feeds on grasses growing in high altitude areas, and produces milk, meat, fur and other animal products, among which the yak milk is known as "natural concentrated milk", containing abundant proteins, fats, lactose and minerals, rich in nutrients [4,5]. Yak yogurt, type IV fermented milk, is fermented from yak milk along with a variety of lactic acid bacteria and yeasts by traditional method. Due to rich ferment bacteria contents, yak yogurt is a treasure house of natural bacteria resources. Yak yogurt is high in lactic acid bacteria which has excellent fermentation properties [6] and probiotics beneficial to the health $[6,7]$. Collecting Tibetan yak yogurt fermented by traditional method to extract the bacteria inside and establish a bacteria resource library is of important significance to the development of traditional yak yogurt starter culture and the extraction of probiotics.

Morphological observation as well as physiological and biochemical characteristics testing are the major traditional methods to identify the genera of lactic acid bacteria, but some lactic acid bacteria do not show obvious differences in morphology as well as physiological and biochemical characteristics, and it is difficult to understand genetic evolutionary status and relationship of lactic acid bacteria exactly. With the development of DNA sequencing technology, 16S rDNA sequencing has been increasingly applied in the identification of the genera of lactic acid bacteria and incorporated into international gene databases, using $16 \mathrm{~S}$ rDNA as target sequence is convenient to analyze the structure of microbial community. In this study, we selected 32 strains of lactic acid bacteria isolated from traditional fermented yak milk produced in the western Sichuan as experimental materials, and extracted total DNA of lactic acid bacteria, polymerase chain reaction amplification, sequence determination and GeneBank retrieval methods were adopted and phylogenetic tree was constructed to determine the genera of lactic acid bacteria existing in yak milk. This study aimed to understand dominant lactic acid bacteria genera which were contained in yak yogurts produced in Western Sichuan, providing theoretical basis for the development of lactic acid bacteria resources as well as the standardized and industrialized production of yak yogurt.
\end{abstract}




\section{Materials and Methods}

Materials, Reagents and Instruments. Lactic acid bacteria were isolated from traditional fermented yak yogurts preserved in laboratory which were made by 2 herdsman families in Hongyuan county and Zoige county of Sichuan Aba Tibetan and Qiang Autonomous Prefecture as samples, and then purified to get 32 strains of lactic acid bacteria with unknown genera and stored them at $4^{\circ} \mathrm{C}$.

MRS liquid culture medium (biological reagent, Qingdao Hopebio Corp, China); genomic DNA extraction kit, RNaseA, protease-K, agarose, DNA Lodaing Buffer and 50xTAE buffer solution (Beijing Solarbio Co., Ltd, China); GelRed (Biotium, USA); $\lambda$ DNA/HindIII, 100 bp DNA Ladder (Tiangen Biotech (Beijing) Co., Ltd, China); primer 1495R, 27F (Shanghai Sangon Biotech Co,. Ltd, China).

Instruments and Equipment. Aseptic table (UD-850, Suzhou purification equipment Co., Ltd., China); water separating type constant temperature incubator (GHP-9160, Shanghai Qixin Scientific Instrument Co., Ltd., China); grads PCR instrument (S1000 Thermal Cycler, Bio-Rad, USA); horizontal electrophoresis tank (Mini-Sub Cell GT Cel, Bio-Rad, USA); Gel imaging system (Gene Genius, SynGene, UK); ultra pure water system (Biocel, Millipore, USA).

\section{Method.}

Activated Microscopic Examination of Lactic Acid Bacteria. Diluents of appropriate gradients were selected and sterilized Pipette tip was used to draw $100 \mu \mathrm{L}$ of diluents under the sterile conditions, and coated it on MRS solid plate culture medium to culture for $48-72 \mathrm{~h}$ at $30^{\circ} \mathrm{C}$, the morphology of bacterial colonies was observed and recorded (by taking photos). Bacterial colonies from the surface and inside of solid plate were taken out by inoculating loop and inoculated in MRS liquid medium, and then cultured in shaker with the rotational speed of $300 \mathrm{r} / \mathrm{min}$ at $30^{\circ} \mathrm{C}$ for $24-48$ $\mathrm{h}$; the above steps were repeated to activate 2 generations of bacterial colonies, and smear Gram staining was performed to identify $\mathrm{G}+$ bacteria, which was continued to be activated till pure colonies (no other bacteria mixed under microscopy) was obtained and saved.

Extraction of Genomic DNA from Lactic Acid Bacteria. The $1.5 \mathrm{~mL}$ bacteria solution cultured in MRS liquid culture medium was taken and centrifuged at $12000 \mathrm{rpm}$, and then the supernatant was discarded and the bacteria were collected. DNA was extracted by adopting genomic DNA extraction kit manufactured by Beijing Solarbio Co., Ltd. The extracted DNA was transferred to $1.5 \mathrm{~mL}$ sterilized $\mathrm{EP}$ tubes, which were numbered in sequence and stored in refrigerator at minus $20^{\circ} \mathrm{C}$.

PCR Amplification. The 16S rDNA genes of lactic acid bacteria were amplified by adopting PCR. In $25 \mu \mathrm{L}$ PCR amplification system, each primer: $0.5 \mu \mathrm{L}$, genomic DNA: $1.0 \mu \mathrm{L}, 10 \times$ plus Buffer Taq (including Mg2+): $2.5 \mu \mathrm{L}$, dNTP Mixture (2.5 mM each): $2.0 \mu \mathrm{L}$, Taq plus $(2.5 \mathrm{u} / \mathrm{ul}, 1.0$ $\mu \mathrm{L}$ ), added with $17.5 \mu \mathrm{L}$ ddH2O.

The above solution was mixed evenly and centrifuged, and then placed on PCR instrument for amplification. Amplification was performed at $94^{\circ} \mathrm{C}$ for $5 \mathrm{~min}$; and then repeated at a total of 30 times (at $94^{\circ} \mathrm{C}$ for $30 \mathrm{~s}$; at $55^{\circ} \mathrm{C}$ for $30 \mathrm{~s}$; at $72^{\circ} \mathrm{C}$ for $1 \mathrm{~min}$ ), and finally performed at $72^{\circ} \mathrm{C}$ for $7 \mathrm{~min}$. When the reaction ended, the products were electrophoresed in $1 \%$ agarose gel under $80 \mathrm{~V}$ for $30 \mathrm{~min}$, and compared with the blank control group, and then detected by gel images system [8,9].

Sequencing and Identification of PCR Products. After electrophoresis by $1 \%$ agarose gel, PCR products were sent to BGI company for sequencing the 16S rDNA genes of 32 strains of lactic acid bacteria. The sequencing results were input into www.ncbi.nlm.nih.gov, and BLAST (Basic Local Alignment Search Tool) was adopted to search GeneBank database for sequence homology analysis to determine the genera of lactic acid bacteria.

Construction of Phylogenetic Tree. Gene sequences at the same sections of 10 strains of lactic acid bacteria were retrieved from GeneBank database, ClustalX1.83 software was applied to conduct multiple sequence comparison, MEGA5.05 software was adopted to construct the 
homologous sequence phylogenetic tree of lactic acid bacteria, and bootstrap analysis was performed to test confidence with bootstrap data sets of 1000 times.

\section{Results and Analysis}

Morphology and Structure of Lactic Acid Bacteria. As shown in Fig. 1 and 2, after bacteria were inoculated in MRS solid culture medium, single colonies showed which had neat edges and smooth surfaces, in white, translucent or creamy yellow colors, ranging from 0.5 to $3 \mathrm{~mm}$ in diameters, with the central parts higher than or as high as the edges. Under the microscope, the cells were stained in blue and purple color, in rod-like or sphere-like shapes without spores, consistent with the characteristics of lactic acid bacteria.

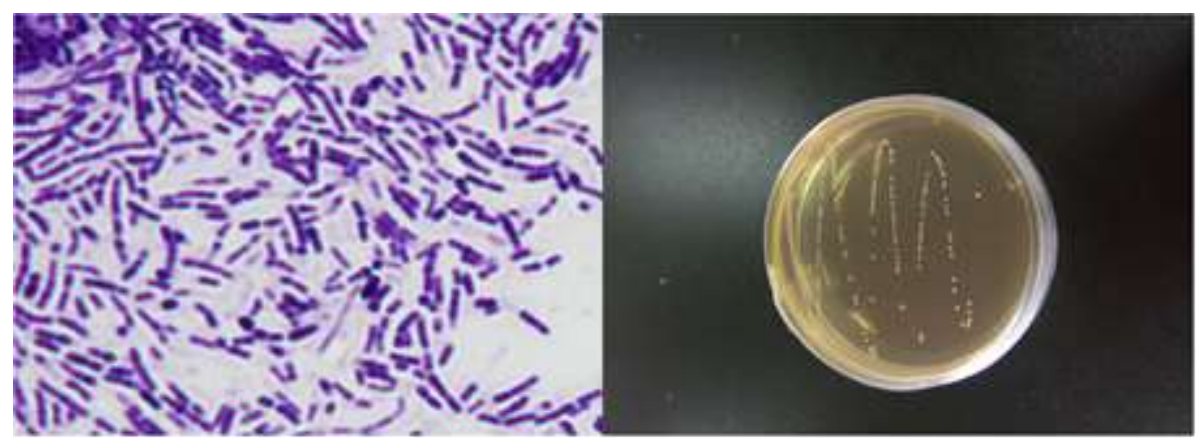

Figure 1. Microscopic observation of Lactobacillus strain $11(\times 1000)$

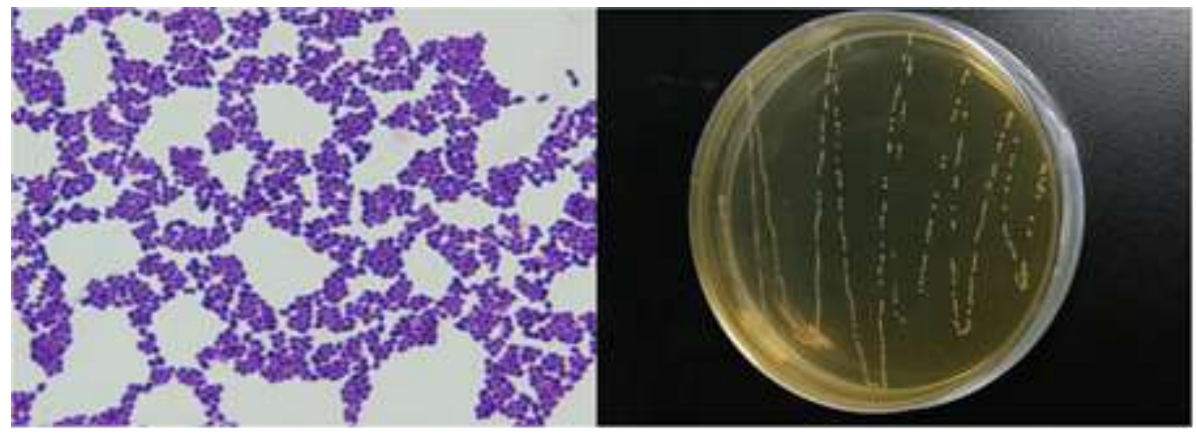

Figure 2. Microscopic observation of Lactococcus strain $1(\times 1000)$

PCR Amplification Products. After extraction by DNA kit and PCR amplification by gel electrophoresis, the results showed that lactic acid bacteria and Lactococcus isolated and purified from Yak yogurt were suitable for the above PCR amplification procedures. After agarose gel electrophoresis, the amplified products were taken pictures by SynGene from GeneSnap gel imaging system as shown in Fig. 3. Lactic acid bacteria contained in Yak yogurt were successfully amplified in the above PCR amplification procedures; the control group showed no interference bands, and samples showed single 16S rDNA band; the lengths of fragments of amplified DNA from 1000 to $2000 \mathrm{bp}$, which were preliminarily identified as $16 \mathrm{~S}$ rDNA, without pollution to bacteria strains or non-specific amplification. 

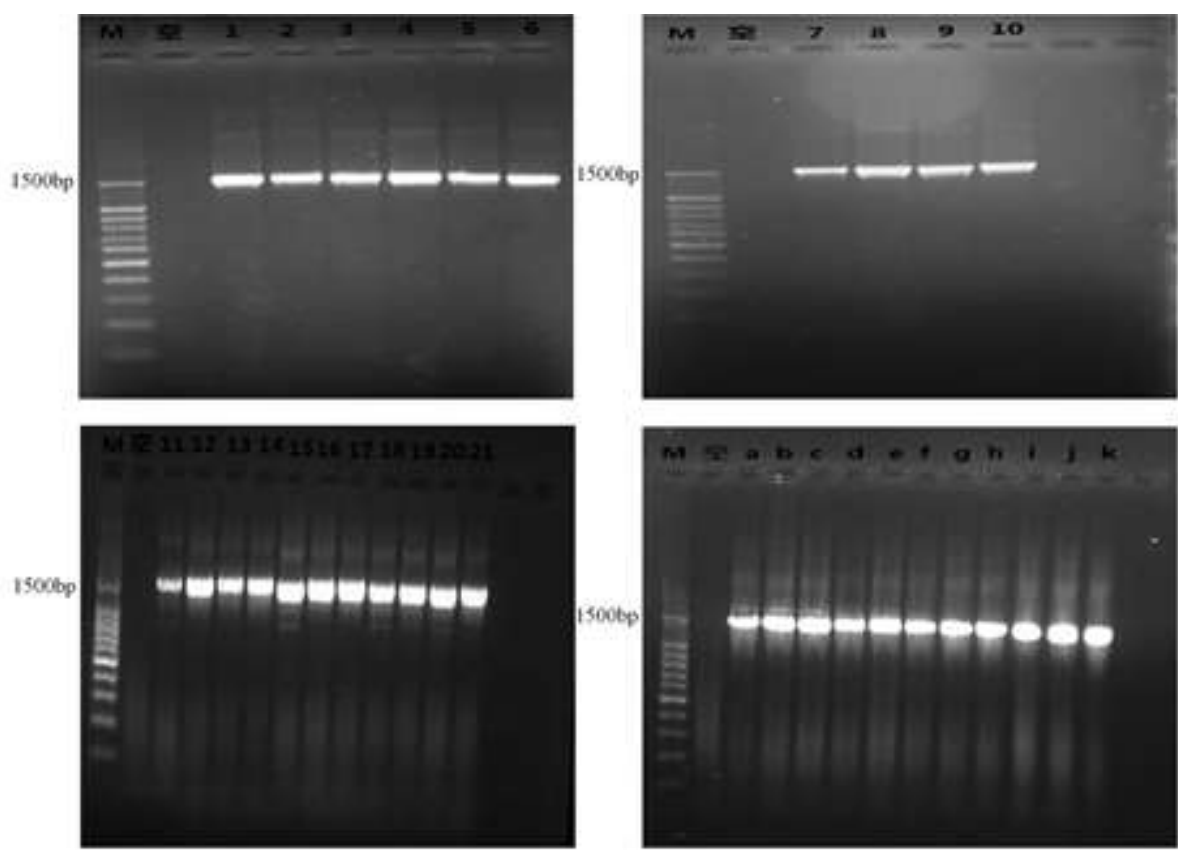

M: 100 bp DNA Ladder; 空: Blank; 1 21: Numbers for 1 21 strains ;

a-k: Numbers for 22 32 strains

Figure 3. Electrophoresis of $16 \mathrm{~S}$ rDNA-PCR product of the 32-strain lactic acid bacteria

Results of 16S rDNA Sequencing of Lactic Acid Bacteria and the Comparison of the Results of Storage. PCR products of successfully amplified bacterial strains were sent to BGI Company for two-way sequencing, and then compared with NCBI database. The retrieval results of GeneBank nucleic acid sequence database by adopting BLAST are as shown in Table 1.

Table 1 The identification results of 32-strain lactic acid bacteria by 16S rDNA sequences

\begin{tabular}{|c|c|c|c|}
\hline No. & Identities & Identification results & GenBank \\
\hline 1 & $99 \%$ & Enterococcus faecium & KT278849.1 \\
\hline 2 & $98 \%$ & Enterococcus faecium & JX275805.1 \\
\hline 3 & $98 \%$ & Enterococcus faecium & JX275805.1 \\
\hline 4 & $99 \%$ & Enterococcus faecium & KM495940.1 \\
\hline 5 & $99 \%$ & Bacillus cereus & KM349186.1 \\
\hline 6 & $98 \%$ & Enterococcus durans & KR858845.1 \\
\hline 7 & $99 \%$ & Enterococcus faecium & KM495940.1 \\
\hline 8 & $99 \%$ & Enterococcus faecium & KP221614.1 \\
\hline 9 & $99 \%$ & Enterococcus durans & CP012384.1 \\
\hline 10 & $99 \%$ & Enterococcus faecium & KJ728981.1 \\
\hline 11 & $99 \%$ & Lactobacillus plantarum & KM485571.1 \\
\hline 12 & $98 \%$ & Enterococcus durans & CP012384.1 \\
\hline 13 & $98 \%$ & Enterococcus faecium & KJ728981.1 \\
\hline 14 & $99 \%$ & Enterococcus faecium & EU789396.1 \\
\hline 15 & $99 \%$ & Enterococcus durans & KP764096.1 \\
\hline 16 & $99 \%$ & Lactobacillus fermentum & KJ026605.1 \\
\hline 17 & $99 \%$ & Lactococcus lactis subsp. & KP716586.1 \\
\hline 18 & $99 \%$ & Lactis & KC417004.1 \\
\hline
\end{tabular}




\begin{tabular}{|l|l|c|c|}
\hline \multicolumn{4}{|c|}{ Table 1, cont. } \\
\hline 19 & $99 \%$ & Lactobacillus paracasei & KR006318.1 \\
\hline 20 & $99 \%$ & Lactobacillus casei & KF673518.1 \\
\hline 21 & $99 \%$ & Bacillus cereus & KM349186.1 \\
\hline 22 & $99 \%$ & Lactobacillus fermentum & KJ026605.1 \\
\hline 23 & $99 \%$ & $\begin{array}{c}\text { Leuconostoc } \\
\text { pseudomesenteroides }\end{array}$ & KF150182.1 \\
\hline 24 & $99 \%$ & Leuconostoc mesenteroides & KC456622.1 \\
\hline 25 & $99 \%$ & Leuconostoc mesenteroides & KF149686.1 \\
\hline 26 & $99 \%$ & Lactococcus lactis & KC417004.1 \\
\hline 27 & $98 \%$ & Enterococcus durans & KR858845.1 \\
\hline 28 & $98 \%$ & Bacillus cereus & KF499032.1 \\
\hline 29 & $99 \%$ & Enterococcus durans & CP012366.1 \\
\hline 30 & $99 \%$ & Enterococcus faecium & KP221614.1 \\
\hline 31 & $95 \%$ & Lactobacillus plantarum & JX003603.1 \\
\hline 32 & $95 \%$ & Lactobacillus fermentum & KF148954.1 \\
\hline
\end{tabular}

As shown in Table 1, 30 strains lactic acid bacteria strains had 98\% homology with those in GenBank database in terms of the sequences of $16 \mathrm{~S}$ rDNA D1/D2 regions, and the 31st and 32nd strain had only $95 \%$ homology, which did not meet the requirements of identification, so the identification was invalid. The molecular biology identification results of 30 strains of lactic acid bacteria are summarized in Table 2 .

Table 2 The summary of 30-strain lactic acid bacteria identified by $16 \mathrm{~S}$ rDNA

\begin{tabular}{|c|c|c|c|}
\hline Genus & Strain name & Number & Proportion \\
\hline \multirow{3}{*}{ Lactobacillus } & L. Fermentum & 2 & $6.25 \%$ \\
\cline { 2 - 4 } & L.Plantarum & 1 & $3.13 \%$ \\
\cline { 2 - 4 } & L. Casei & 1 & $3.13 \%$ \\
\cline { 2 - 4 } & L.Paracasei & 1 & $3.13 \%$ \\
\hline \multirow{3}{*}{ Lactococcus } & Lac. Lactis & 2 & $6.25 \%$ \\
\hline \multirow{2}{*}{ Leuconostoc } & Lac. Lactis subsp. Lactis & 1 & $3.13 \%$ \\
\cline { 2 - 4 } & Leuc.Pseudomesenteroides & 1 & $3.13 \%$ \\
\cline { 2 - 4 } & Leuc. Mesenteroides & 2 & $6.25 \%$ \\
\hline Bacillus & B. Cereus & 3 & $9.38 \%$ \\
\hline \multirow{2}{*}{ Enterococcus } & E. Faecium & 10 & $31.25 \%$ \\
\cline { 2 - 4 } & E.Durans & 6 & $18.75 \%$ \\
\hline
\end{tabular}

Note: A total of 5 genera and 11 species were identified, 2 strains of identification is invalid.

As shown in Table 2, 30 strains of lactic acid bacteria belonged to 11 species of 5 genera. The samples were rich in lactic acid Bacteria, Cocci and Bacilli contained in yak yogurt were dominated by Enterococcus (50.00\%) and Lactobacillus (15.63\%), followed by Lactococcus, Leuconostoc and Bacillus (9.38\%). Enterococcu faecium (31.25\%) accounted for a majority of Enterococcus. Yang et al. [11] collected 17 yak cheese samples from Tibet, Yunnan and Xinjiang, and cultured them in MRS medium at $37^{\circ} \mathrm{C}$ for $48 \mathrm{~h}$, isolating Lactobacillus casei, Lactobacillus plantarum, Lactobacillus plantarum, Lactobacillus fermentum and Pediococcus. Chen et al. [7] analyzed the microorganisms in yak yogurts and cheeses collected from Tibet by using the same methods, and isolated Lactobacillus paracasei, Lactobacillus and Lactococcus lactisetc. Lv et al. [12] used MRS 
medium and MC medium to culture fermented "cheeses" collected from Shangri-La at $37^{\circ} \mathrm{C}$ for 72 $\mathrm{h} \pm 3 \mathrm{~h}$ under both anaerobic and aerobic conditions, and identified Lactococcus lactis, Lactobacillus, Lactobacillus fermentation and other dominant strains. The genera of lactic acid bacteria contained in Yak fermented dairy products produced in different regions differed, which were related to the geographical locations, climates and production conditions such as inoculation amount, inoculation time, fermentation temperature, fermentation environment and other factors [13]. Bao et al. [14] reported the diversity of lactic acid bacteria contained in 20 yak yoghurt samples collected from Sichuan Hongyuan grassland, they used MRS medium and M17 medium to culture yak yoghurt samples at $30^{\circ} \mathrm{C}$ under anaerobic condition for three days, finding that Streptococcus thermophilus accounted for a majority of bacteria in yak yogurts. While Ao et al. [15] found that Enterococcus, Lactobacillus fermenti and Lactobacillus paracasei were the dominant lactic acid bacteria in yak yoghurts produced in Sichuan Hongyuan grassland. These experiments had results different from those of the study which found Enterococcus was the major lactic acid bacteria in yak yogurt, indicating that naturally fermented yak yogurt produced by different families in the same area contained different genera of lactic acid bacteria, with great differences in the structures of bacterial colonies [16]. In addition, the diversity of isolated lactic acid bacteria is also related to different culture methods and culture mediums, as MRS culture medium is mainly used for the isolation of lactic acid bacteria, while M17 culture medium majorly used for the separation of Coccus [14].

Enterococcus faecium, one among the key bacteria which maintain the balance of intestinal flora [17], has sound antibacterial effects and lowers cholesterols, and synthetizes vitamins and proteins which human body needs [18]. In addition, Enterococcus faecium survives in adverse conditions, with strong resistance to acid, high temperature and drought, so Yak yogurt is high in Enterococcus faecium [19]. Leuconostoc mesenteroides, also known as flavor bacterium, aroma bacterium and flavor producing strain ,can ferment citric acid to produce flavor compounds, and also serves as bacteriostatic agent and healthcare agent [20]. Bacillus cereus is a conditional pathogen which causes food poisoning, and it is a common source of pollution [21], closely related to the hygiene, fermentation methods and fermentation environment of herdsmen. It can be concluded that in addition to affecting the flavor and nutrition values, the microorganisms also affect the safety and quality of yogurts. So the identification of genera of lactic acid bacteria in Yak yogurt not only enriches the resources of lactic acid bacteria, but also provides theoretical basis for the preparation of standards of fermented yak milk nutrition quality, safety and health.

Phylogenetic Analysis Results. It can be learnt from Fig. 4 that the identified 30 strains of lactic acid bacteria are divided into 2 clades, indicating that there are 2 genetic types. 8th, 27th, 6th, 7th, 14th, 4th, 12nd, 1st, 30th, 2nd, 3rd, 10th, 13rd, 15th, 9th and 29th bacteria belong to the same clade with Enterococcus faecium and Enterococcus durans, suggesting that they are genetically related. But 27th, 4th, 2nd, 3rd, 10th, 13rd, 15th, 9th and 29th are relatively genetically distant with other strains in this clade, suggesting high genetic diversity within the same genera. The 19th strain is between Lactobacillus casei and L. paracasei, and the 17th strain between Lactococcuslactis and Lactococcuslactis subsp. Lactis, which also indicated genetic diversity. The 11st strain can be classified as Lactobacillus plantarum, and the 23rdstrain as Leuconostoc pseudomesenteroides. Similarly, the 24th strain and Leuconostoc mesenteroides belong to the same genus. The location of isolated strains in the phylogenetic trees is consistent with identification results, confirming $16 \mathrm{~S}$ rDNA sequence identification method has high reliability. Similar to other bacteria, lactic acid bacteria exchange genetic materials from the environment through horizontal gene transfer to adapt to the new environment and to survive. Chen et al. [22] proposed that Enterococcus faecium in the natural fermented milk of different resources evolved to adapt to the environment. Zhang et al. [23] found in the study to genetic diversity of Leuconostoc mesenteroides that isolated strains had rich genetic diversity. Therefore, due to the unique geographical environment of Western Sichuan and the differences in the methods of making fermented yoghurt by herdsmen, lactic acid bacteria contained in naturally fermented yak yoghurt have rich genetic diversity through natural selection and domestication [16]. 


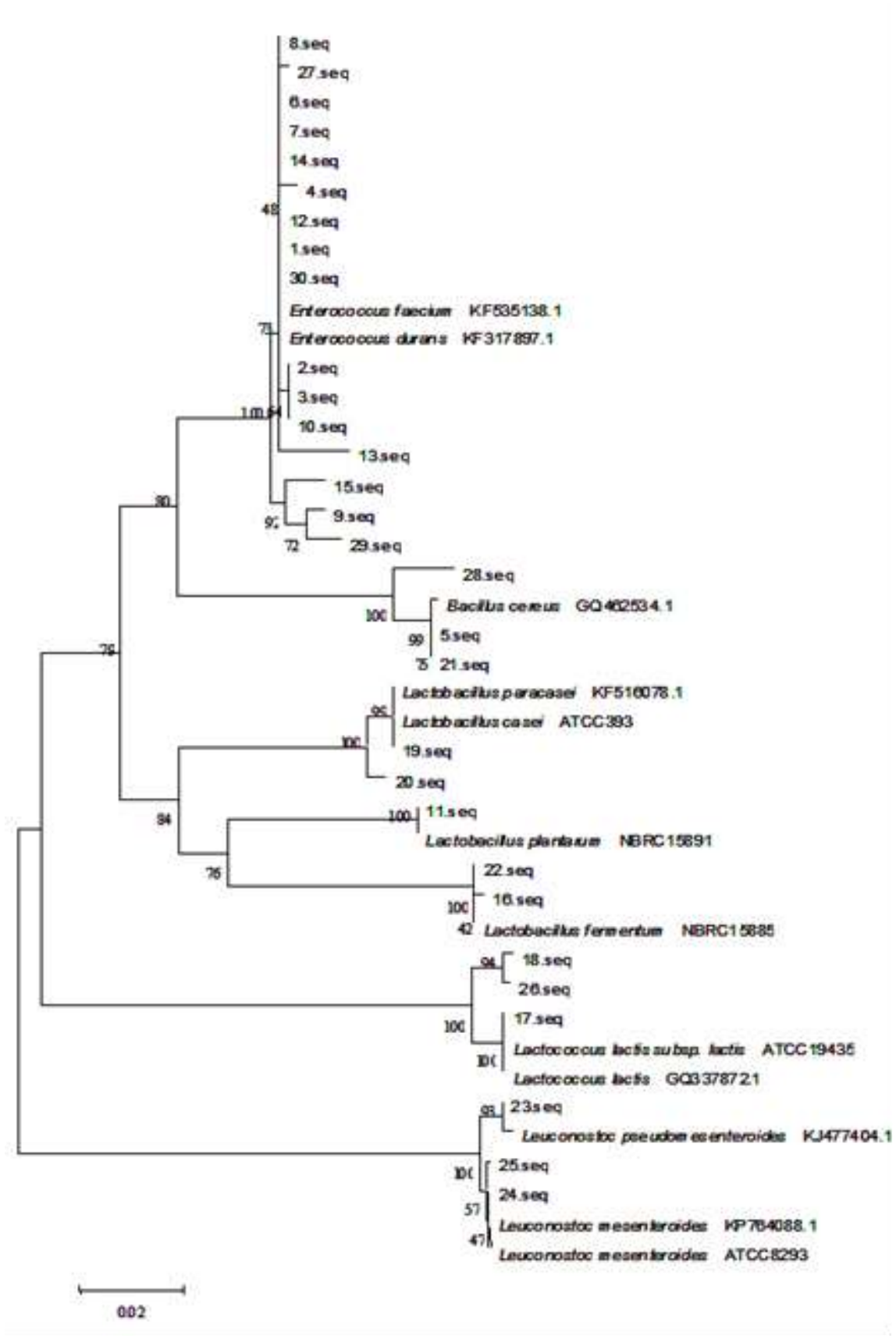

Figure 4. Phylogenetic Tree of 36 Lactic Acid Bacteria Strains Based on 16S rDNA D1/D2 Domain Sequences

\section{Conclusions}

We identified 32 strains of lactic acid bacteria isolated from traditional fermented yak yogurts produced in Western Sichuan, finding that 30 strains of lactic acid bacteria had over $97.5 \%$ homology with identified lactic acid bacteria in the GenBank interms of the sequences of $16 \mathrm{~S}$ rDNA D1/D2 region, only 2 had 95\% homology, which did not meet the requirements of identification, so the identification was invalid. Therefore, compared with traditional identification methods, 16SrDNA sequence analysis method is more accurate and more reliable, with obvious advantages in the identification of lactic acid bacteria strains at the level of species.

The identified 30 strains of lactic acid bacteria were divided into 5 genera, such as Lactobacillus, Lactococcus, Leuconostoc, Bacillus and Enterococcus; and 11 species, such as Lactobacillus fermentum (6.25\%), Lactobacillus plantarum (3.13\%), Lactobacillus casei $(3.13 \%)$, Lactobacillus paracasei (3.13\%) Lactobacillus lactis (6.25\%), Lactococcus Lactis subsp Lactis (3.13\%), 
Leuconostoc pseudomesenteroides (3.13\%), Leuconostoc mesenteroides (6.25\%), Bacillus cereus (9.38\%), Enterococcus faecium (31.25\%) and Enterococcus durans (18.75\%), indicating yak yoghurts produced in Western Sichuan are high is lactic acid bacteria, and Lactobacillus and Enterococcus account for a majority, which have provided theoretical basis for the development and utilization of lactic acid bacteria contained in yak yoghurt, as well as the preservation of strain bacteria resources.

\section{Acknowledgements}

This work was partly supported by Special Fund for Agro-scientific Research in the Public Interest (201203009), the People's Livelihood Science and technology innovation Foundation of Chongqing (cstc2015shmszx 80021) and Fundamental Research Funds for the Central Universities, China ( XDJK2017D129).

\section{References}

[1] WU C S, SHU C, LI J, et al. The research progress and prospect of Yak Yogurt lactic acid bacteria[J]. Food Industry, 2012(9):129-133.

[2] YU L, LUO Z, MENG Y, et al. Chemical and microbiological composition analyses of yak milk in tibet[J]. China Dairy Industry, 2006, 34(9): 8-11.

[3] WEN W, LUO X, XIA B, et al. Post-mortem oxidative stability of three yak (Bos grunniens) muscles as influenced by animal age[J]. Meat science, 2015, 105: 121-125.

[4] QIU Q, ZHANG G, MA T, et al. The yak genome and adaptation to life at high altitude[J]. Nature Genetics, 2012, 44(8): 946-949.

[5] LI H, MA Y, LI Q, et al. The chemical composition and nitrogen distribution of Chinese yak (Maiwa) milk[J]. International Journal of Molecular Sciences, 2011, 12(8): 4885-4895.

[6] ZHANG H, XU J, WANG J, et al. A survey on chemical and microbiological composition of kurut, naturally fermented yak milk from Qinghai in China[J]. Food Control, 2008, 19(6): 578-586.

[7] CHEN Z L, CHENG C, MA K, et al. Isolation and identification of lactic acid bacteria from fermented yak milk products in tibet area[J]. Food Science, 2008, 29(12): 408-412.

[8] LIU S P, LUO Z Y. Agarose gel electrophoresis test technique[J]. Practical Preventive Medicine, 2006, 13(4): 266-267.

[9] DU L H, LIU F. Application of 16S rRNA gene in identification of bacteria[J]. Journal of Dairy Science and Technology, 2006(5): 207-209.

[10] YANG R X. Identification of endophytic bacteria from Brassica napus using 16S rDNA sequence analysis[D].Xi'an: Northwest A\&F University, 2005

[11] YANG J X, CHEN Z L, YANG H Y, et al. Identification and characterization of lactic acid bacteria from chinese yak milk cheeses[J].Food Science, 2013, 34(9): 198-204.

[12] LV J M, LI J B, ZHU C, et al. Isolation and identification of Lactobacillus from yak milk dregs[J]. China Dairy Cattle, 2011(20): 57-60.

[13]BAO X H. Diversity analysis of lactic acid bacteria in yak milk products in Gansu and Sichuan province[D]. Inner Mongolia Agricultural University, 2012.

[14]BAO Q, YU J ,LIU W, et al. Isolation and identification of predominant lactic acid bacteria in traditional fermented yak milk products in Sichuan province of China[J]. Dairy Sci Technol, 2012, 92(3): 309-319.

[15] AO X, ZHANG X, SHI L, et al. Identification of lactic acid bacteria in traditional fermented yak milk and evaluation of their application in fermented milk products[J]. Journal of Dairy Science, 2012, 95(3): 1073-1084.

[16]ZHANG H P. Biodiversity of lactic acid bacteria in naturally fermented dairy products[J]. Chinese Bulletin of Life Sciences, 2015, 27(7): 837-846.

[17]HU M, YAN H, YANG J. Optimization of cultural conditions of Enterococcus Faecom on high density culture[J]. China Dairy Industry, 2012, 40(4): 12-17. 
[18]TANG Y H, TANG Y L. Regulatory effects of Enterococcus Faecium JT1701 on intestinal bacteria of humans[J]. Journal of Shanghai Jiaotong University, 2001, 35(7): 1066-1070.

[19] YUAN J L, KANG B. Enterococcus and related micro ecological regulator [J]. Chinese Journal of Microecology,1998, 10(1): 59-60.

[20]LI W B, SONG M L, GAO R K. Research and application process of leuconostoc mesenteroides[J]. Food Industry, 2007(4): 3-4.

[21]ZHAO YM. The research on the exposure of Bacillus cereus in dairy products[D]. Central South University of Forestry and Technology, 2014.

[22] CHEN X, SONG Y, XU H, et al. Genetic relationship of Enterococcus faecalis from different sources revealed bymultilocus sequence typing[J]. Journal of Dairy Science, 2015, 98(8): 5183-5193.

[23]ZHANG W, LIU W, SONG Y, et al. Multilocous sequence typing of dairy-associated Leuconostoc mesenteroides population reveals clonal structure with intragenic homologous recombination[J]. Journal of Dairy Science, 2015, 98(6): 2284-2293. 